\section{SCARECROW is involved in positioning the stem cell niche in the Arabidopsis root meristem}

\author{
Sabrina Sabatini, Renze Heidstra, \\ Marjolein Wildwater, and Ben Scheres ${ }^{1}$ \\ Department of Molecular Cell Biology, Utrecht University, \\ 3584 CH Utrecht, The Netherlands
}

Stem cells self-renew and produce daughter cells that differentiate. How stem cells are specified and maintained is a central question in developmental biology. Plant stem cells occupy a small region or niche in larger zones of mitotic activity called meristems. Here we provide molecular evidence that in the Arabidopsis root meristem, the stem cell population depends on a central group of cells, the quiescent center (QC), which positions the stem cell niche. We show that the putative transcription factor SCARECROW (SCR), first identified by its role in radial patterning, is required cell-autonomously for distal specification of the QC, which in turn regulates stem cell fate of immediately surrounding cells.

Received October 21, 2002; revised version accepted November 29, 2002.

Stem cell identity in various organisms is maintained in microenvironments called niches (Spradling et al. 2000). Their maintenance depends on local signaling events emanating from nearby cells that can be considered part of the niche (Spradling et al. 2000). Cap cells (Xie and Spradling 1998, 2000) and somatic hub cells (Kiger et al. 2001; Tulina and Matunis 2001) in Drosophila, distal tip cells in Caenorhabditis elegans (Kimble and White 1981), and cells expressing the homeodomain transcription factor WUSCHEL in the Arabidopsis shoot apical meristem (Mayer et al. 1998; Schoof et al. 2000) are examples of cells locally required for the maintenance of stem cells. In these cases, it remains to be established how the signaling cells themselves are specified to define stem cell location.

In the Arabidopsis root meristem, the "initial cells" are the stem cells that give rise to all cell types of the root; they surround a small group of mitotically less active cells, the quiescent center (QC), and can be unequivocally identified (Fig. 1a; Dolan et al. 1993). Laser ablation experiments suggested that the QC is a source of cell nonautonomous signals, which prevent differentiation and hence maintain the surrounding stem cells (van den Berg et al. 1997). Hence, the QC and the sur-

[Keywords: Initial; quiescent center; auxin; meristem; pattern formation] ${ }^{1}$ Corresponding author.

E-MAIL b.scheres@bio.uu.nl; FAX 31-30-2513655.

Article and publication are at http://www.genesdev.org/cgi/doi/10.1101/ $\operatorname{gad} .252503$. rounding cells that contact it can be considered a stem cell niche. The SCARECROW (SCR) gene encodes a putative transcription factor (Di Laurenzio et al. 1996) that is first expressed in QC precursor cells during embryogenesis, after which it extends to the initial cells for the ground tissue (cortex and endodermis) and the endodermis (Wysocka-Diller et al. 2000); this expression pattern persists in the postembryonic root (Fig. 1a; Di Laurenzio et al. 1996). In scr-1 mutants, the asymmetric cell division of the daughter of the cortex/endodermis initial does not occur, resulting in a single cell layer with mixed identity (Fig. 1d; Di Laurenzio et al. 1996). Importantly, cells in the src-1 QC region are aberrant in shape and roots ultimately cease growth (Scheres et al. 1995; Di Laurenzio et al. 1996). Here, we provide evidence that these effects are not caused by the cortex/endodermis defect but rather reflect a direct requirement for SCR activity in QC cells for their specification and maintenance of surrounding stem cells.

\section{Results and Discussion}

In line with a possible QC identity defect in scr mutants, we noted that the QC expression domain of the $S C R$ promoter driving GFP was absent in $s c r-1$ (Fig. 1d). Of three independent QC-expressed promoter traps, only QC184 continues to mark the QC (Fig. 1g,j), whereas markers QC25 and QC46 are absent in the scr-1 mutant (Fig. 1b,c,e,f), indicating partial loss of QC identity. To assess the effect of QC specification defects on stem cell maintenance, we analyzed scr-1 cells immediately below the QC, at the position of columella initials in the wild type. These cells acquired differentiation markers such as amyloplasts and marker Q1630, which are normally excluded from the initials and present only in mature columella cells (Fig. 1h,i,k,1). It is noteworthy that laser ablation of single QC cells provoked the same columella differentiation response (van den Berg et al. 1997). Our results suggest that $s c r-1$ mutants lack an appropriately specified QC and fail to maintain columella initials. Morphologically abnormal cells at the position of the QC and absence of columella initials were detected in three other scr alleles (data not shown). To assess whether all stem cells failed to be maintained in $s c r$ mutants, we followed root development over time. In 8-dayold scr-1 seedling roots, root hairs and xylem strands characteristic of fully differentiated epidermal and vascular cells, respectively, approach the root tip as meristem size decreases and root growth ceases (see below). These data suggest that in the scr-1 mutant, stem cell activity is ultimately lost, thereby leading to loss of meristem maintenance and root growth.

To understand whether SCR expression in the QC is sufficient to specify QC identity and whether this maintains all surrounding stem cells, we reexpressed the $S C R$ gene in the QC region of $s c r-1$ roots using a trans-activation system. To this end, different GAL4,UAS::GFP driver constructs originating from the enhancer trap collection established by J. Haseloff (http://www.plantsci. cam.ac.uk/Haseloff) were introduced in scr-1 mutant plants carrying a UAS::SCR construct. The scr$1, U A S:: S C R$ plants without driver construct were indistinguishable from scr-1 plants, indicating that no back- 

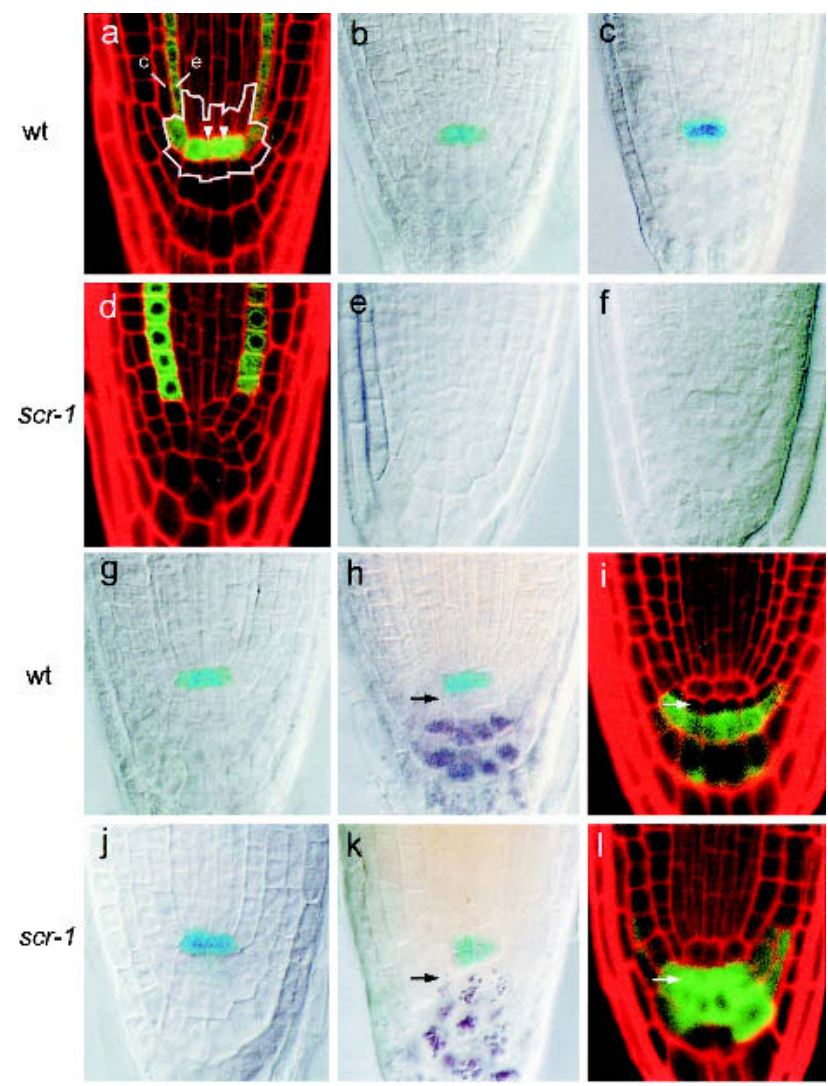

Figure 1. Defects in QC identity and columella stem cell activity in the scr-1 mutant. $(a-c, g-i)$ Wild-type (wt) roots. $(d-f, j-l) s c r-1$ roots. (a) SCR::GFP expression in wild-type (wt) roots. The white line includes the stem cells surrounding the QC (arrowheads). c, cortex; e, endodermis. (d) SCR ::GFP expression in scr-1 roots. $(b, e)$ QC25 expression. $(c, f)$ QC46 expression. Lack of QC marker expression in $s c r-1$ roots $(d-f)$ indicates defect in QC identity. $(g, j)$ QC184 expression retained in $s c r-1 .(h, k)$ Double labeling of QC and differentiated columella cells visualized by QC184 and amyloplast staining, respectively, reveal defective columella stem cells (arrows) in scr-1. (i,l) Columella-specific enhancer trap Q1630 also reveals defective columella stem cells (arrows) in scr-1.

ground expression of SCR was obtained from the UAS promoter. The J2341 enhancer trap line showed GFP expression in QC and columella initials in wild-type plants (Fig. 2a), whereas in the scr-1 mutant, GFP was detected in the cells at the position of the inappropriately specified QC (marked by QC184) and variably in some vascular cells (Fig. 2e). When the J2341 driver was introduced in $s c r-1, U A S:: S C R$ plants, GFP expression monitored GAL4 activity and hence ectopic $S C R$ expression in the mutant background (Fig. 2i). In these plants, the QC46 marker reappeared, indicating that $\mathrm{QC}$ identity was restored, but the SCR-dependent separation of ground tissue in endodermal and cortical cell layers was not restored (Fig. $2 \mathrm{~m}$ ). Amyloplast staining and the ordered structure of the columella root cap compared to scr-1 revealed that columella initials were now present (Fig. $2 \mathrm{i}, \mathrm{m})$. Furthermore, root growth was maintained, although growth rate and meristem size were reduced compared to wild-type plants (Fig. 3a-c). Thus, SCR expression in the QC, or in columella stem cells (that arise after rescue), or in a column of provascular cells of the scr-1 mutant rescued QC and stem cell identity and prevented consumption of the meristem by dissipation of the stem cell pool.

To investigate whether SCR expression in the columella could rescue stem cell activity in this tissue, we expressed SCR in the columella of $s c r-1, U A S:: S C R$ roots using the J1092 driver. QC identity was not restored, as judged from the absence of QC46 expression (Fig. $2 b, f, j, n)$. In addition, irregular columella cells as well as the presence of amyloplasts in cells directly below the inappropriately specified QC revealed a lack of columella initials (Fig. 2j,n). Furthermore, comparable to the scr-1 mutant, roots differentiated and arrested growth around $8 \mathrm{~d}$ postgermination $(\mathrm{dpg})$, suggesting that stem cell activity was not restored (Fig. 3a-c). To exclude the possibility that the provascular expression domain of J2341 contributed to restoration of QC and stem cell identity, we crossed plants carrying a reconstituted promoter of the QC184 promoter trap driving GAL4VP16 (Fig. 2c) with $s c r-1, U A S:: S C R, U A S:: G F P$ plants (Fig. $2 \mathrm{~g}$. Only when both constructs were combined, GFP expression marked ectopic SCR expression in the QC, ground tissue, and columella initials but, importantly, not in provascular cells (Fig. 2k). In these plants, QC46 expression was apparent and no amyloplasts were found in cells directly below the QC, suggesting that QC and columella initials were restored (Fig. 2o). Due to the expression of $S C R$ in the cortex/endodermis initials, the periclinal division in the ground tissue was also restored (Fig. 2k,o). Furthermore, root growth was maintained although growth rate and meristem size was reduced compared to wild-type plants (data not shown). We conclude that the recovery of QC identity and the stem cell niche in $s c r-1$ plants depends on the expression of $S C R$ in the QC and not in columella or vascular cells.

To further demonstrate that $S C R$ expression is required cell-autonomously for QC identity, we used the N9094 driver to express SCR in the $s c r-1$ mutant ground tissue (Fig. 2d,h). QC46 expression and, by inference, QC identity could not be restored, and columella differentiation markers indicated the lack of columella initials (Fig. $21, \mathrm{p})$. However, asymmetric cell division in the ground tissue was restored because the Casparian strip, an endodermis-specific cell wall deposit (Di Laurenzio et al. 1996; Helariutta et al. 2000), was detected only in the cells between the stele and the presumptive cortex (data not shown). Thus, the level of $S C R$ expression in the ground tissue of $s c r-1, U A S:: S C R$ was appropriate to rescue the radial patterning defect. However, although root growth and meristem size of these plants were initially higher compared to $s c r-1$ plants, $19 \mathrm{~d}$ after germination the roots stopped growing and the root meristem differentiated (Fig. 3a-c). This observation is in stark contrast to the indeterminate growth observed in scr-1, $U A S:: S C R$ plants expressing $S C R$ in the QC. Our data strongly suggest that $S C R$ expression in the ground tissue contributes to overall meristem activity but cannot support indeterminate growth and maintenance of the stem cell niche. The assumption that the reexpression of $S C R$ in the separate QC and ground tissue domains accurately reflects two separable contributions of the endogenous gene to meristem growth and maintenance is supported by the observation that $s c r-1 / U A S:: S C R$ plants, in which both the J2341 and N9094 drivers have been introduced, display wild-type root growth rate and meristem size (Fig. 3a-c). 


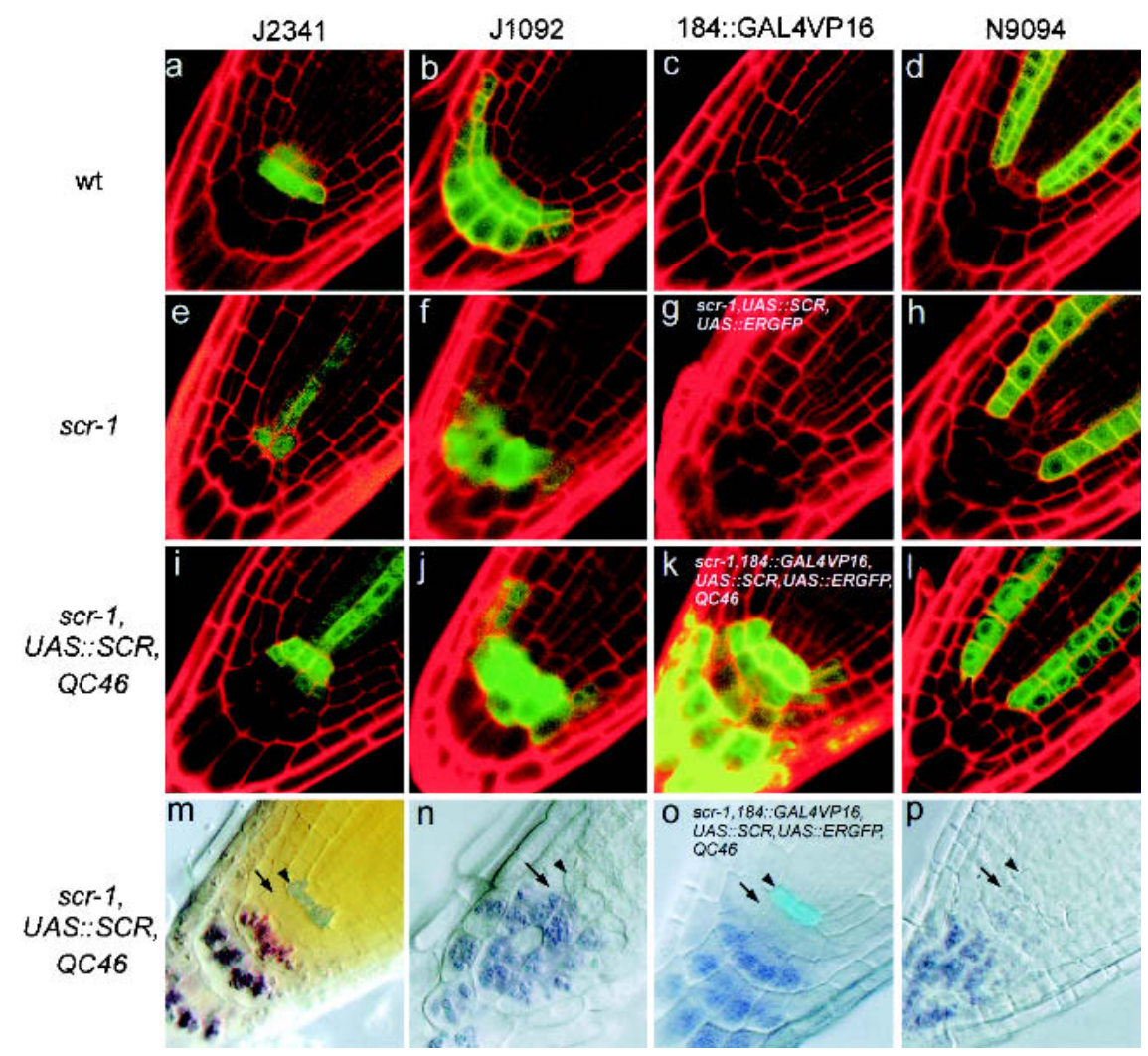

Figure 2. SCR expression in the QC is required and sufficient to establish QC identity and stem cell activity. $(a, b, d)$ GFP expression in roots of wild-type $(\mathrm{wt})$ plants carrying the driver J2341 $(a)$, J1092 (b), and N9094 (d), each with endogenous GFP reporter. (c) Root tip of wild-type $(w t)$ plant carrying the driver 184::GAL4VP16 without GFP reporter. $(e, f, h)$ GFP expression in roots of $s c r-1$ plants carrying the driver J2341 (e), J1092 (f), and N9094 (h). $(g)$ Root tip of scr-1 plant carrying the UAS::SCR,UAS::ERGFP construct. $(i, j, 1)$ GFP expression marking SCR activity in roots of $s c r-1, U A S:: S C R, Q C 46$ plants carrying the driver J2341 (i), J1092 (j), and N9094 (1). (k) Idem in roots of scr-1,UAS:: SCR,UAS::ERGFP, QC46 plants carrying the driver 184::GAL4VP16. $(m-p)$ Double labeling of QC and differentiated columella cells visualized by QC46 and amyloplast staining of roots with genotypes depicted in (i-1). Arrowheads indicate position of QC cells, arrows indicate position of columella stem cells. Restoration of functional QC and columella stem cells (indicated by QC46 staining and absence of amyloplasts at the position of columella stem cells) are observed with SCR expression in QC cells, driven by J2341 $(\mathrm{m})$ and 184::GAL4VP16 $(\mathrm{o})$.

We conclude that SCR expression in the QC is required cell-autonomously for QC identity. Furthermore, we conclude that $S C R$ activity enables the QC to maintain the surrounding stem cells in a noncell-autonomous fashion, and that SCR expression in stem cells themselves or in other regions of the meristem cannot substitute for this activity. Apparently, SCR action in the QC results in the production of as yet unidentified signals to maintain the neighboring stem cells, confirming previously reported laser ablation studies (van den Berg et al. 1997).

Recent elegant work revealed that the SCR-related SHORTROOT (SHR) protein, required for endodermal specification and up-regulation of SCR expression in the ground tissue, is expressed in vascular cells and may move as a protein to the surrounding cell layer, including the QC (Helariutta et al. 2000; Nakajima et al. 2001). shr mutants display irregular morphology in the QC/columella region, and roots cease growth prematurely (Benfey et al. 1993; Helariutta et al. 2000). Consistent with a requirement for $S H R$ in QC specification and stem cell maintenance, SCR::GFP, QC25, QC46 expression, and columella initials are absent in shr-1 (data not shown). Furthermore, like in the $s c r-1$ mutant, in 5-day-old shr-1 seedling roots, root hairs, and xylem strands approach the root tip as meristem size decreases and root growth ceases $(\mathrm{He}-$ lariutta et al. 2000). QC and stem cell identity and root growth were however not restored in $s h r, U A S:: S C R$ when we reexpressed $S C R$ in the QC region (data not shown). Our findings suggest that the role of SHR in QC function and stem cell maintenance is not confined to its requirement for $S C R$ transcription in the QC region and that additional $S H R$-dependent factors are needed to control QC identity and function. This requirement of both SHR and SCR for QC identity is analogous to the requirement of both gene products for ground tissue patterning in the radial dimension.

SHR and SCR action pattern the entire tissue layer surrounding the vascular tissue, which raises the question of how a limited region of this domain is selected to become QC and define the position of the stem cells, whereas others respond by taking on ground tissue fates and division patterns. Auxin distribution has emerged as the potentially relevant positional cue to pattern the QC and other cell types in the postembryonic root, as changes in auxin distribution by polar auxin transport inhibition or exogenous applied auxin-induced respecification of distal cell types (Sabatini et al. 1999). In particular, endodermal cells acquired QC identity, based on marker gene expression and maintenance of the newly respecified surrounding columella stem cells (Sabatini et al. 1999). Therefore, ectopic specification of QC cells correlated with ectopic respecification of stem cells, suggesting that QC identity may be sufficient to specify stem cell identity in the root meristem. We propose a model in which all SCR-expressing cells are competent to acquire QC identity where the actual choice depends on auxin distribution, selecting a subset of cells within the SCR expression domain. In this model, the $S C R$ gene is a radial ("circumvascular") patterning input that combines with auxin-dependent cues in the apical-basal axis to specify the cells that control stem cell identity. It is of note that, in a similar vein, interplay between auxindependent and meristem-derived cues may play a role in the positioning of lateral organs at the shoot apex (Reinhardt et al. 2000).

Our data provide molecular evidence that QC cells in the root meristem maintain the neighboring stem cells in a defined niche, in analogy to other plant and animal stem cell systems, and in addition, our data suggest a model of how such a niche is specified. 
A

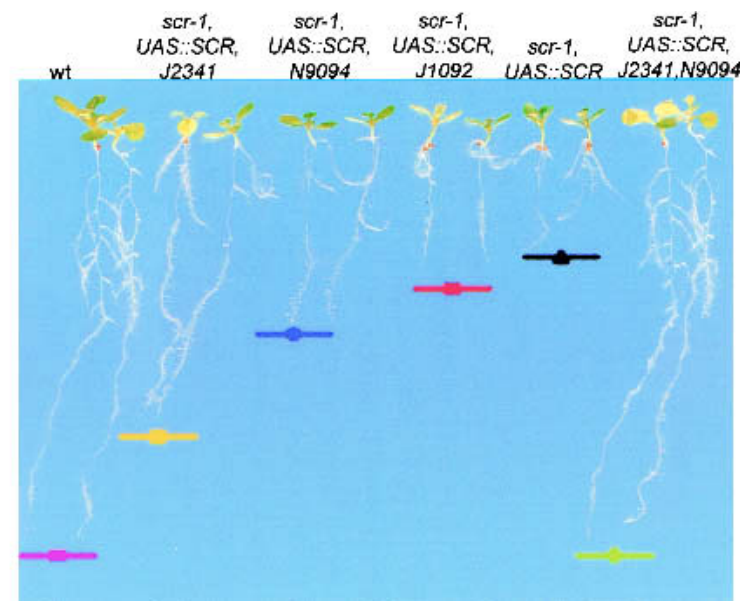

\section{C}

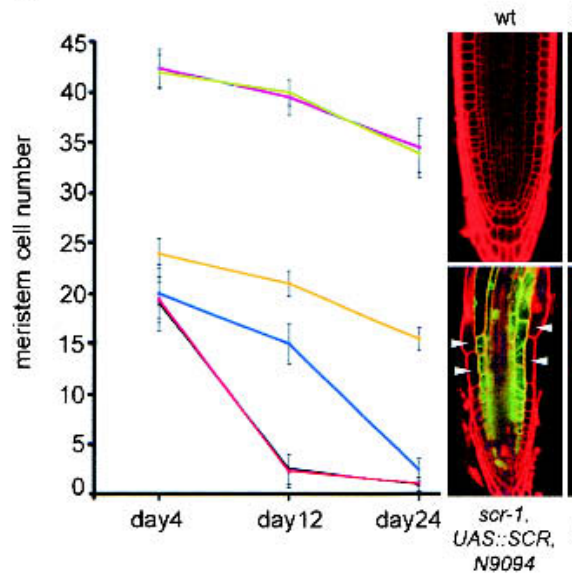

scr-1, SCr-1 UAS::SCR, UAS::SCR J1092

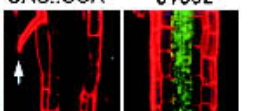

Figure 3. $S C R$ expression in the $\mathrm{QC}$ is required and sufficient to maintain indeterminate growth and meristematic cells. Root length $(a, b)$ and root meristem cell number $(c)$ measured in time of wild-type (wt), scr-1,UAS::SCR, scr-1,UAS::SCR,J2341, scr-1, UAS::SCR,J1092, scr-1,UAS::SCR, N9094, and scr-1,UAS::SCR, 12341,N9094 plants. Root growth and stem cell activity was only maintained when SCR expression was restored in QC cells, i.e., genotypes scr-1,UAS::SCR,J2341 and scr-1,UAS::SCR,J2341, N9094. SCR expression in any other cell type failed to prevent meristem cell differentiation and cessation of root growth $(c)$. Arrow in $s c r-1, U A S:: S C R$ root indicates a root hair, characteristic of fully differentiated epidermal cells. Other signs of cell differentiation are the GFP expression in the vasculature of $s c r-1, U A S:$ : $S C R, J 1092$ roots (vascular GFP expression in the J1092 enhancer trap line is found only in fully differentiated vascular cells) and cell elongation in $s c r-1, U A S:: S C R, N 9094$ root (arrowheads). Root tips depicted in the right panel in $c$ were analyzed $24 \mathrm{dpg}$. wt, wild-type.

\section{Materials and methods}

Plant material and growth conditions

Arabidopsis thaliana mutants scr-1 and shr-1 and constructs containing the SCR cDNA clone and SCR::GFP were kindly provided by Philip Benfey (Duke University, USA). QC46, QC25, and QC184 promoter trap lines were selected from the INRA T-DNA collection (Bechtold et al. 1993). Enhancer trap lines J1092, J2341, and Q1630 were kindly provided by Jim Haseloff (http://www.plantsci.cam.ac.uk/Haseloff). N9094 was obtained through the Nottingham stock center.

Seeds were sterilized in $5 \%$ sodium hypochloride, imbibed at $4^{\circ} \mathrm{C}$ in the dark in sterile water containing $0.1 \%$ agarose for $2-5 \mathrm{~d}$, and germinated on plates containing $0.5 \times$ Murashige and Skoog (MS) salt mixture, $1 \%$ sucrose, and $0.5 \mathrm{~g} / \mathrm{L} 2$-(N-morpholino) ethanesulfonic acid (MES) at $\mathrm{pH} 5.8$, in $0.8 \%$ agar. Plates were incubated in a near vertical position at $22^{\circ} \mathrm{C}$ with a cycle of $16 \mathrm{~h}$ light $/ 8 \mathrm{~h}$ dark. Starch granules and $\beta$-glucoronidase activity were visualized as described (Willemsen et al. 1998).

\section{Ectopic SCR expression}

The pGreen binary vector set and expression/resistance cassettes (Hellens et al. 2000; http://www.pgreen.ac.uk) were used as vehicles in Agrobacterium-mediated plant transformation [strain C58(pMP90); Koncz and Schell 1986], which was performed according to the floral dip method (Clough and Bent 1998). The modified GAL4VP16 transcriptional activator gene for improved plant expression (http://www.plantsci.cam. ac.uk/Haseloff) was amplified from enhancer trap line J2341 and cloned in pGreenII carrying the nos-kanamycin resistance cassette. Primers

were: GAL4VP16F2, AAGCTTGGATCCAACAATGAAGCTCCTGTC GAL4VP16R, CTACCCACCGTACTCGTCAATTCC. A 2160-bp fragment upstream of the QC184 T-DNA insertion was amplified and cloned in front of GALVP16 to form the 184::GAL4VP16 construct and transformed into wild-type (Col-0) plants. Primers were: 184F3, AGTTCG CAGTAATCTCCTAATGAAACAAAA; prQC184R, AAATATGTATG GAGAGCAGAGAAAATTGATC.

The UAS promoter was constructed of six repeated 17-bp GAL4 binding sites, interspaced by $2 \mathrm{bp}$, from the S.cereviciae GAL1 promoter (Giniger et al. 1985), followed by the -46 minimal 35 S promoter (Odell et al. 1985). A UAS promoter cassette was constructed by replacing the $35 \mathrm{~S}$ promoter in the $35 \mathrm{~S}$ cassette (Hellens et al. 2000). ER-GFP was constructed combining the amplified GFP5-HDEL from enhancer trap line J2341 with a synthetic ER targeting signal peptide sequence derived from Arabidopsis basic chitinase (http://www.plantsci.cam.ac.uk/Haseloff). Primers were: mGFP5ERF, ATATATGAATTCAGTAAAGGAGAAG AACTTTTCACTGGAGTTG; mGFP5ERR, TTAAAGCTCATCATGTT TGTATAGTTCATCCA.

The SCR cDNA and ERGFP were cloned in the UAS cassette and then transferred into pGreenII carrying the nos-basta resistance cassette forming $U A S:: S C R$ and $U A S:: S C R / U A S:: E R G F P$, respectively.

Wild-type (WS) plants were transformed with the UAS::SCR construct, and three different transgenic lines were crossed to $s c r-1$. The $s c r-1, U A S:: S C R$ plants obtained where then crossed with scr-1,22341, $s c r-1, J 1092$ and $s c r-1, N 9094$ plants, previously prepared by genetic crossing. Roots of seedlings resulting from the F1 generation were analyzed 5-7 dpg using a Leica inverted confocal microscope. 
The same strategy was used for ectopic SCR expression in the shr-1 mutant background.

The UAS::SCR/UAS::ERGFP construct was used to transform scr-1 plants, and three of the resulting transgenic lines were crossed with 184::GAL4VP16 plants. Roots of scr-1,184::GAL4VP16,UAS::SCR, $U A S:: E R G F P$ seedlings resulting from the $\mathrm{F} 2$ generation were then analyzed 5-7 dpg.

To assess QC restoration, scr-1,UAS::SCR, 22341, scr-1,UAS::SCR, J1092, scr-1,UAS::SCR,N9094, and scr-1,184::GAL4VP16,UAS::SCR, UAS::ERGFP plants were crossed with scr-1,QC46. To avoid changes in phenotype due to gene disruption, every construct introduced in the $s c r-1$ and shr-1 mutants was kept heterozygous.

Root length and meristem size analysis

Root length of wild-type, scr-1,UAS:: SCR, scr-1,UAS:: SCR,J2341, scr1,UAS::SCR,J1092, scr-1,UAS::SCR,N9094, and scr-1,UAS::SCR,J2341, N9094 seedlings was measured every other day for $24 \mathrm{~d}$ as described (Willemsen et al. 1998). Wild-type control plants used in these experiments came from the F2 population obtained from the cross between the respective enhancer trap line $(\mathrm{C} 24)$ and the $s c r-1$ mutant (WS). No differences in root length were found in wild-type plants derived from different F2 populations.

The number of root meristematic cells was obtained by counting epidermis cells showing no signs of rapid elongation.

\section{Acknowledgments}

We thank Frits Kindt, Ronald Leito, Piet Brouwer, and Wil Veenendaal for photography and assistance with Adobe PhotoShop, and Maarten Terlou for help with root length measurements. We are indebted to Jim Haseloff for generously making available GFP marker lines, and to Roger Hellens for providing pGreen vectors before publication. We are indebted to Philip Benfey, Tal Nawy, David Welch, and Rolf Zeller for valuable discussions and comments on the manuscript. S.S. was sponsored by an EMBO fellowship ALTF 302-2000; M.W. and B.S. are supported by an NWO-PIONIER grant.

The publication costs of this article were defrayed in part by payment of page charges. This article must therefore be hereby marked "advertisement" in accordance with 18 USC section 1734 solely to indicate this fact.

\section{References}

Bechtold, N., Ellis, J., and Pelletier, G. 1993. In planta Agrobacterium mediated gene transfer by infiltration of adult Arabidopsis plants. $C R$ Acad. Sci. (Paris) 316: 1194-1199.

Benfey, P.N., Linstead, P.J., Roberts, K., Schiefelbein, J.W., Hauser, M.T., and Aeschbacher, R.A. 1993. Root development in Arabidopsis: Four mutants with dramatically altered root morphogenesis. Development 119: 57-70.

Clough, S.J. and Bent, A.F. 1998. Floral dip: A simplified method for Agrobacterium-mediated transformation of Arabidopsis thaliana. Plant J. 16: 735-743.

Di Laurenzio, L., Wysockadiller, J., Malamy, J.E., Pysh, L., Helariutta, Y., Freshour, G., Hahn, M.G., Feldmann, K.A., and Benfey, P.N. 1996. The SCARECROW gene regulates an asymmetric cell division that is essential for generating the radial organization of the Arabidopsis root. Cell 86: 423-433.

Dolan, L., Janmaat, K., Willemsen, V., Linstead, P., Poethig, S., Roberts, K., and Scheres, B. 1993. Cellular organization of the Arabidopsis root. Development 119: 71-84.

Giniger, E., Varnum, S.M., and Ptashne, M. 1985. Specific DNA binding of GAL4, a positive regulatory protein of yeast. Cell 40: 767-774.

Helariutta, Y., Fukaki, H., Wysocka-Diller, J., Nakajima, K., Jung, J., Sena, G., Hauser, M.T., and Benfey, P.N. 2000. The SHORT-ROOT gene controls radial patterning of the Arabidopsis root through radial signaling. Cell 101: 555-567.

Hellens, R.P., Edwards, E.A., Leyland, N.R., Bean, S., and Mullineaux, P.M. 2000. pGreen: A versatile and flexible binary Ti vector for Agrobacterium-mediated plant transformation. Plant Mol. Biol. 42: 819-832.

Kiger, A.A., Jones, D.L., Schulz, C., Rogers, M.B., and Fuller, M.T. 2001. Stem cell self-renewal specified by JAK-STAT activation in response to a support cell cue. Science 294: 2542-2545.

Kimble, J.E. and White, J.G. 1981. On the control of germ cell development in Caenorhabditis elegans. Dev Biol. 81: 208-219.

Koncz, C. and Schell, J. 1986. The promotor of $\mathrm{T}_{\mathrm{L}}$-DNA gene 5 controls the tissue-specific expression of chimaeric genes carried by a novel type of Agrobacterium binary vector. Mol. Gen. Genet. 204: 383-396.

Mayer, K.F., Schoof, H., Haecker, A., Lenhard, M., Jurgens, G., and Laux, T. 1998. Role of WUSCHEL in regulating stem cell fate in the Arabidopsis shoot meristem. Cell 95: 805-815.

Nakajima, K., Sena, G., Nawy, T., and Benfey, P.N. 2001. Intercellular movement of the putative transcription factor SHR in root patterning. Nature 413: 307-311.

Odell, J.T., Nagy, F., and Chua, N.H. 1985. Identification of DNA sequences required for activity of the cauliflower mosaic virus $35 \mathrm{~S}$ promoter. Nature 313: 810-812.

Reinhardt, D., Mandel, T., and Kuhlemeier, C. 2000. Auxin regulates the initiation and radial position of plant lateral organ. Plant Cell 12: $507-518$.

Sabatini, S., Beis, D., Wolkenfelt, H., Murfett, J., Guilfoyle, T., Malamy, J., Benfey, P.N., Leyser, O., Bechtold, N., Weisbeek, P., et al. 1999. An auxin-dependent distal organizer of pattern and polarity in the Arabidopsis root. Cell 99: 463-472.

Scheres, B., Di Laurenzio, L., Willemsen, V., Hauser, M.T., Janmaat, K., Weisbeek, P., and Benfey, P.N. 1995. Mutation affecting the radial organization of the Arabidopsis root display specific defects throughout the embryonic axis. Development 121: 53-62.

Schoof, H., Lenhard, M., Haecker, A., Mayer, K.F., Jurgens, G., and Laux, T. 2000. The stem cell population of Arabidopsis shoot meristems in maintained by a regulatory loop between the CLAVATA and WUSCHEL genes. Cell 100: 635-644

Spradling, A., Drummond-Barbosa, D., and Kai, T. 2000. Stem cells find their niche. Nature 414: 98-104.

Tulina, N. and Matunis, E. 2001. Control of stem cell self-renewal in Drosophila spermatogenesis by JAK-STAT signaling. Science 294: 2546-2549.

van den Berg, C., Willemsen, V., Hendriks, G., Weisbeek, P., and Scheres, B. 1997. Short-range control of cell differentiation in the Arabidopsis root meristem. Nature 390: 287-289.

Willemsen, V., Wolkenfelt, H., de Vrieze, G., Weisbeek, P., and Scheres, B. 1998. The HOBBIT gene is required for formation of the root meristem in the Arabidopsis embryo. Development 125: 521-531

Wysocka-Diller, J.W., Helariutta, Y., Fukaki, H., Malamy, J.E., and Benfey, P.N. 2000. Molecular analysis of SCARECROW function reveals a radial patterning mechanism common to root and shoot. Development 127: 595-603.

Xie, T. and Spradling, A.C. 1998. decapentaplegic is essential for the maintenance and division of germline stem cells in the Drosophila ovary. Cell 94: 251-260.

. 2000. A niche maintaining germ line stem cells in the Drosophila ovary. Science 290: 328-330. 


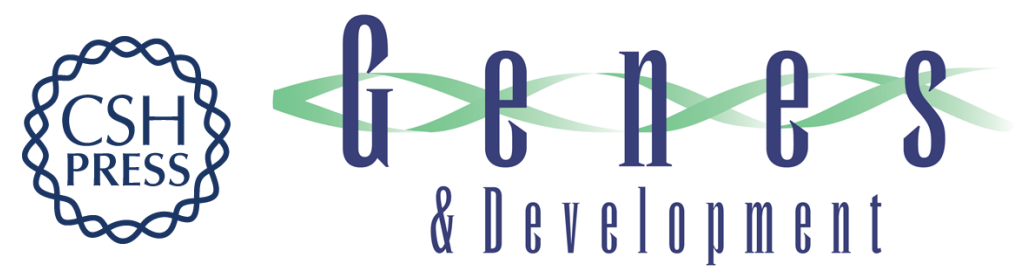

\section{SCARECROW is involved in positioning the stem cell niche in the Arabidopsis root meristem}

Sabrina Sabatini, Renze Heidstra, Marjolein Wildwater, et al.

Genes Dev. 2003, 17:

Access the most recent version at doi:10.1101/gad.252503

References This article cites 24 articles, 9 of which can be accessed free at: http://genesdev.cshlp.org/content/17/3/354.full.htmI\#ref-list-1

License

Email Alerting

Receive free email alerts when new articles cite this article - sign up in the box at the top Service right corner of the article or click here.

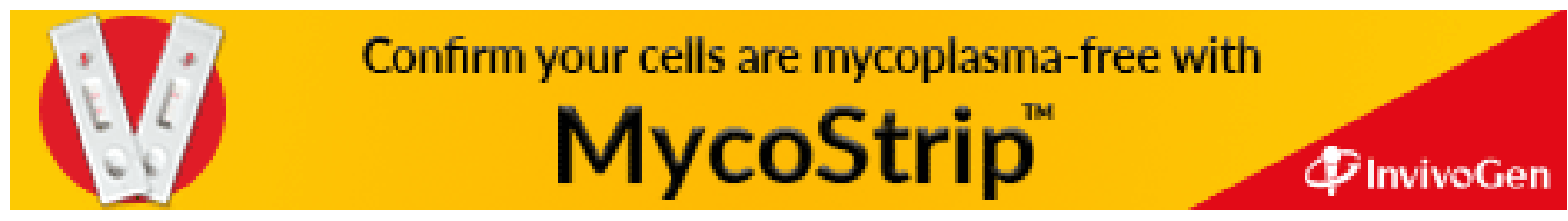

